\title{
Climate Services and Communication for Development: The Role of Early Career Researchers in Advancing the Debate
}

Felix Kwabena Donkor, Candice Howarth, Eromose Ebhuoma, Meaghan Daly, Catherine Vaughan, Lulu Pretorius, Julia Mambo, Dave MacLeod, Andrew Kythreotis, Lindsey Jones, Sam Grainger, Nicola Golding \& Julio Araujo Anderson

To cite this article: Felix Kwabena Donkor, Candice Howarth, Eromose Ebhuoma, Meaghan Daly, Catherine Vaughan, Lulu Pretorius, Julia Mambo, Dave MacLeod, Andrew Kythreotis, Lindsey Jones, Sam Grainger, Nicola Golding \& Julio Araujo Anderson (2019) Climate Services and Communication for Development: The Role of Early Career Researchers in Advancing the Debate, Environmental Communication, 13:5, 561-566, DOI: 10.1080/17524032.2019.1596145

To link to this article: https://doi.org/10.1080/17524032.2019.1596145

Published online: 21 May 2019.

Џll Article views: 415

View Crossmark data \lceil
Submit your article to this journal 주 


\title{
Climate Services and Communication for Development: The Role of Early Career Researchers in Advancing the Debate
}

\author{
Felix Kwabena Donkor ${ }^{a}$, Candice Howarth ${ }^{b}$, Eromose Ebhuoma $\mathbb{B D}^{\mathrm{c}}$, Meaghan Daly ${ }^{\mathrm{d}}$, \\ Catherine Vaughan $^{\mathrm{e} *}$, Lulu Pretorius ${ }^{\mathrm{f}}$, Julia Mambo ${ }^{\mathrm{g}}$, Dave MacLeod ${ }^{\mathrm{h}}$, \\ Andrew Kythreotis ${ }^{i \neq \S}$, Lindsey Jones ${ }^{j \uparrow}$, Sam Grainger ${ }^{k}$, Nicola Golding' and \\ Julio Araujo Anderson ${ }^{\mathrm{m}}$
}

\begin{abstract}
${ }^{a}$ College of Agriculture and Environmental Sciences (CAES), University of South Africa (UNISA), FloridaJohannesburg, South Africa; ${ }^{b}$ University of Surrey, Guildford, UK; ' $\mathrm{C}$ chool of Tourism and Hospitality, University of

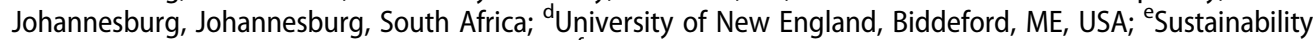
Research Institute, Leeds University, Leeds, UK; ' $\mathrm{f}$ School of Agricultural, Earth and Environmental Sciences, University of KwaZulu-Natal, Durban, South Africa; ${ }^{9}$ The Council for Scientific and Industrial Research (CSIR), Pretoria, South

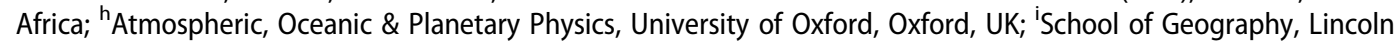
Centre for Water and Planetary Health - College of Science University of Lincoln, Brayford Pool, Lincoln, UK; ${ }^{\mathrm{j}}$ Grantham Research Institute on Climate Change and the Environment, London School of Economics and Political Science, London, UK; ${ }^{k}$ Sustainability Research Institute, School of Earth and Environment, University of Leeds, Leeds, UK; 'Met Office, Exeter-Devon, UK; ${ }^{\mathrm{m}}$ South South North, Cape Town, South Africa
\end{abstract}

\begin{abstract}
Climate services entail providing timely and tailored climate information to end-users in order to facilitate and improve decision-making processes. Climate services are instrumental in socio-economic development and benefit substantially from interdisciplinary collaborations, particularly when including Early Career Researchers (ECRs). This commentary critically discusses deliberations from an interdisciplinary workshop involving ECRs from the United Kingdom and South Africa in 2017, to discuss issues in climate adaptation and climate services development in water resources, food security and agriculture. Outcomes from the discussions revolved around key issues somewhat marginalized within the broader climate service discourse. This commentary discusses what constitutes "effective" communication, framings (user framings, mental models, narratives, co-production) and ethical dimensions in developing climate services that can best serve end-users. It also reflects on how ECRs can help tackle these important thematic areas and advance the discourse on climate services.
\end{abstract}

\section{KEYWORDS}

Climate services; early career researchers; climate communication; knowledge co-production; interdisciplinary

\section{Climate communication and development: the role of climate services}

Climate risks are intricately interwoven with human history (Donkor, Tantoh, \& Ebhuoma, 2017), as societies adapt to short-term variability and long-term change. Nonetheless, there remain significant gaps to effectively mitigate negative consequences of climate change (Fankhauser \& McDermott, 2014). Extreme weather and climate events can compromise socio-economic development.

CONTACT Felix Kwabena Donkor felixdonkor2002@yahoo.co.uk E College of Agriculture and Environmental Sciences, University of South Africa (UNISA), UNISA Science Campus, Corner of Christiaan de Wet Road \& Pioneer Avenue, Florida 1709, South Africa *Present address: International Research Institute for Climate \& Society, Earth Institute at Columbia University, Palisades, NY, USA

‡Present address: Tyndall Centre for Climate Change Research, University of East Anglia, Norwich, UK

${ }^{\S}$ Present address: School of Psychology, Cardiff University, Cardiff, Wales, UK

"Present address: Risk and Resilience Programme, Overseas Development Institute, London, UK

(c) 2019 Informa UK Limited, trading as Taylor \& Francis Group 
Knowledge is a key determinant of societal capacities to adapt to climate risks; however, persistent barriers (e.g. organizational and historical cultural barriers) hinder links between climate information and practical decision-making (Richards \& Carruthers Den Hoed, 2018).

Moving beyond climate information towards "climate services" has gained traction in recent years due to its potential to increase the utilization of climate information (Vaughan \& Dessai, 2014). Climate services supply timely and tailored climate information to scale-up decision-making processes of end-users (Howarth, Viner, Dessai, Rapley, \& Jones, 2017), thereby limiting negative effects and enhancing benefits of climate risks. Climate services are particularly useful to make informed decisions related to disaster risk reduction, agriculture, energy, health, and water issues. However, its potential contribution toward socio-economic development, including lessons learned, ongoing challenges, and future directions requires further exploration.

This Commentary harnesses discussions from a British Council Newton Fund Researcher Links workshop; "Communication, Interpretation, and Use of Climate Information for Development" (held in Cape Town, South Africa, March 2017). The workshop afforded interdisciplinary Early Career Researchers (ECRs) from South Africa and the UK the opportunity to generate insights and learn from workshop participants', mentors' and facilitators' experiences on the opportunities and barriers that inform climate services development. Three areas were identified that warrant critical attention if climate services are to contribute effectively to socio-economic development: communication challenges, framings of climate services, and ethical dimensions. We sign-post innovative trajectories for future climate services research, including the crucial role that inter-disciplinary ECRs can play in advancing the climate services discourse.

\section{Focus 1: communication challenges}

Communicating climate change is crucial given its potential to trigger behavioral changes (Ebhuoma \& Simatele, 2017). However, communicating uncertainty is complicated by contextual misunderstandings, indefensible information (where caveats and limitations lack description), not being co-produced (Jack, 2017), complex messages, and poor understanding on how climate risks are experienced (Ebhuoma \& Simatele, 2017). Mechanisms of knowledge exchange and local experience of weather events rely on the communication of climate science and are important toward co-producing climate responses (Howarth et al., 2017; Pereira, Shackleton, \& Donkor, 2017). Researchers' eagerness to engage with different stakeholders is mediated by factors such as their belief in enjoying the experience (attitude), desire to make a difference through engagement (response efficacy), and having adequate time to engage meaningfully (Besley, Dudo, Yuan, \& Lawrence, 2018). Yet more is needed to improve this to ensure fuller alignment with end-user needs and better representation (and hence understanding) of climate information.

Additionally, visualizing climate information is instrumental for communicating climate information and explaining climate model results (Hewitt, Mason, \& Walland, 2012) to non-experts. It helps reduce interpretation biases so users understand related uncertainty and risks (Daron, Lorenz, Wolski, Blamey, \& Jack, 2015). However, there is a need to better understand how various channels for communicating climate information may affect interpretation and trust, and which methods may be most appropriate across different geographic and institutional scales and contexts (Pereira et al., 2017). Since ECRs are often up to speed with various innovative knowledge and techniques across a range of disciplines, recruiting ECRs can stimulate creative thinking to tackle challenges that may undermine interpretation and trust in climate information.

\section{Focus 2: framing climate services}

It is crucial to move beyond uni-directional approaches to communicating climate information to ensure closer alignment with end-user needs (Fløttum \& Gjerstad, 2016; Whitmarsh \& Corner, 2018). This requires increased reflexivity around framing climate services, including who should 
be involved in setting the agenda around producing climate services and which perspectives, knowledge, and experiences are included/excluded. This requires novel approaches and closer collaboration across disciplines with multiple stakeholders (Termonia et al., 2018) with expertise in developing and implementing climate solutions on the ground, to maximize relevance (Viner \& Howarth, 2014).

\subsection{Narratives}

Narrative approaches to communication, defined as "stories which can explain the situation, define a problem that disrupts the order of the initial situation and then provide a resolution to that problem, which re-establishes order" (Bushell, Satre Buisson, Workman, \& Colley, 2017, p. 42) are increasingly utilized in climate change decision-making. Narratives can enhance inductive approaches to make sense of climate change and adaptive responses. This enables place attachments in appreciating human responses to climate and facilitating local engagement (Howarth \& Black, 2015). Despite this, it will be increasingly important to recognize the differences between instrumental (e.g. Jones \& Peterson, 2017) and exploratory applications of narrative approaches (e.g. Bremer \& Meisch, 2017). Due to the lack of agreement on what is meant by a "narrative" (Howarth, 2017), future research of ECRs can explore whose stories and realities are being told, how these stories are represented, and what kind of climate futures these stories envision.

\subsection{Co-production}

Effectively tailoring climate services to the needs of end-users is considered a primary hurdle (Terrado, Christel, Bojovic, Soret, \& Doblas-Reyes, 2018). Similarly, exclusion of existing knowledge (e.g. local or indigenous knowledge), which continue to shape how the rural poor adapt to climate risks can undermine the legitimacy of the associated processes and resulting climate services products (McNie, 2007; Pereira et al., 2017). Developing approaches that effectively reflect multiple climate knowledge transcends merely tailoring information to actually co-producing knowledge (Daly, West, \& Yanda, 2016). However, there is a prevalent lack of reflection on the theoretical basis and goals of co-production (Bremer \& Meisch, 2017). For example, while co-production may increase the "usability" of climate services, there may be disparities in power within co-production processes (Daly et al., 2016; Goldman, Turner, \& Daly, 2018). Moreover, co-production poses significant limitations for practitioners' uninterested or lacking requisite skills/ resources (Howarth et al., 2017). ECRs trained in interdisciplinary contexts are critical to addressing challenges related to co-production including where and how to invest in and apply coproduction.

\section{Focus 3: ethical dimensions of climate services}

Despite efforts to explore the ethical dimensions of climate services (Tozier de la Poterie \& Daly, 2017), significant gaps remain; examination of differential access and benefits, issues around commodification of climate knowledge, and questions of governance. Furthermore, current approaches to assessing the value of climate services are insufficient to understand the distribution of impacts of climate services (Bruno Soares, Daly, \& Dessai, 2018). Thus, frameworks conceptualized by ECRs to capture how climate services may contribute to equitable socio-economic development are needed.

Another area of ethical concern is the commodification of climate knowledge within the field of climate services. In Europe, climate services are increasingly framed in terms of a "market" (Street, 2016), contradictory to conceptualizations of climate services as a public good. Increased marketization risks exacerbating imbalances in capabilities to produce and benefit from climate services between the global North and South (Vaughan, Dessai, \& Hewitt, 2018). This risk of commodifying climate services requires further work. 


\section{Looking ahead: the role of ECRs in advancing the debate}

ECRs with interdisciplinary training are critical to effectively address "wicked problems" (e.g. natural resource management and poverty alleviation) because they hardly regard disciplinary boundaries. Further, the vehement calls to utilize interdisciplinary research to address "wicked problems" could be hinged on team science theory. It posits that highly integrated and interactive research teams have some common characteristics that enhance the success and sustainability of their work. These include trust, a shared vision, conflict management, team building, and unambiguous expectations for sharing achievements (Bennett \& Gadlin, 2012). The effectiveness of integrating multiple ways of knowing is mediated by the fact that science, as an epistemology, requires a collaborative effort. However, widespread " ... contradictions in commitments to epistemic diversity and the privileging of science, demonstrating tensions between conceptual commitments to participatory approaches within sustainability science and practices of engagement" exist (Suldovsky, McGreavy, \& Lindenfeld, 2018, p. 499). Nonetheless, ECRs from diverse backgrounds can inject robust, innovative, and sustainable solutions to tackle challenges and advance the field of climate services because:

1. ECRs are un-entrenched in narrow fields of expertise, in the process of "finding their feet". Addressing climate communication challenges requires innovative and interdisciplinary approaches, to which an ECR could be well suited.

2. ECRs are more flexible: they usually have less teaching and supervising responsibilities, thereby providing opportunities for them to learn, contribute, and grow rapidly within the shortest timeframe.

3. ECRs have opportunities to stimulate their careers by refining soft skills (e.g. communication skills), traveling (the workshop which gave rise to this commentary), and reading diverse literature. This can be mobilized to address climate services challenges and staying updated on the latest trends in the field.

However, more research is needed on the significance of ECR collaboration, given that climate research has often suffered from epistemic communities where more established scientists are often disengaged from emerging early career research within the climate science-policy process. In this sense, research is needed about both the integration of ECR's work in producing climate information and in how to effectively embed ECRs within the process of implementing their research in policy dialogues. Greater collaboration between established scientists and ECRs will widen the evidence base of climate risks that are used upstream in the climate science communication process (e.g. policy formulation and implementation) to support more distributed and co-productive end-user climate action and policy in the future (e.g. Howarth et al., 2017; Ivancevic, 2017). This has long been an issue in the IPCC process where more established researchers dominate the "science-side" governance of the science-policy process used to formulate climate policy (Petersen, Blackstock \& Morisetti, 2015).

It is recommended that the IPCC and other climate service providers have rules in place that enable increased ECR contribution, e.g. a certain proportion of nascent/state-of-the-art research should come from ECRs, particularly from ECR women and/or ECRs from developing countries, who have often been ostracized from the paternalistic and masculine practices of the IPCC (GayAntaki \& Liverman, 2018). It is crucial to have greater number of forums for ECRs from diverse backgrounds to come together to discuss the available types of climate information, and how it is produced for end-users. The workshop that resulted in this commentary has been particularly useful in bringing together ECRs - in terms of co-producing new narratives of climate information - who would never ordinarily collaborate. This is something that the IPCC could fund to make itself more user-friendly (Petersen et al., 2015).

Today's ECRs are tomorrow's field leaders, hence investment should be channeled to maintain their ability to address "wicked problems". ECRs are often quick to utilize emerging technologies and methodologies to support climate services development. However, two issues persist: (i) lack 
of permanent positions and career instability, meaning that academic retention is low and related skills and expertise are often lost by academics who leave. As such, academic institutions can do more to offer a wider range of research positions, in particular providing incentives for researchers with cross-disciplinary skillsets or those with first-hand experience in policy realms (and other nontraditional scholarly backgrounds) that might otherwise be dissuaded from a career in academia; (ii) geographical brain-drain means the most promising ECRs in developing countries are drawn toward Western institutions, due to prestige and career development opportunities. Donor efforts to ensure that Southern partners are more substantially embedded into large climate service research programs and afforded opportunities to take charge of project design and delivery aspects will be useful to address the geographic brain-drain problem - such as it is the case for both the Weather and Climate Information Services for Africa (WISER) and Future Climate for Africa (FCFA) programs.

In conclusion, this commentary has addressed some of the core issues in climate services research, including communication challenges, the need for co-production and ethical dimensions in developing climate services. To ensure sound climate communication to enable effective decision-making and resilience to climate change, ECRs should play a central role because effective inclusion of interdisciplinary ECRs is needed to advance the discourse on climate services.

\section{Acknowledgements}

Our special appreciation to the workshop coordinators Suraje Dessai and Coleen Vogel as well as the workshop mentors Joe Daron, Rachel James, Admire Nyamwanza and Katherine Vincent. We also wish to thank the British Council and Newton Fund for supporting the workshop on "Communication, interpretation and use of climate information for development” which took place in Cape Town, South Africa, 6-8/03/2017 (Reference number: RLWK6 - 261875805).

\section{Disclosure statement}

No potential conflict of interest was reported by the authors.

\section{Funding}

This work was supported by British Council and Newton Fund: [Grant Number Reference number: RLWK6 261875805].

\section{ORCID}

Eromose Ebhuoma (D) http://orcid.org/0000-0002-3446-3463

\section{References}

Bennett, L. M., \& Gadlin, H. (2012). Collaboration and team science: From theory to Practice. Journal of Investigative Medicine, 60(5), 768-775.

Besley, J. C., Dudo, A., Yuan, S., \& Lawrence, F. (2018). Understanding scientists' willingness to engage. Science Communication, 40(5), 559-590.

Bremer, S., \& Meisch, S. (2017). Co-production in climate change research: Reviewing different perspectives. WIRES: Climate Change, 38(Suppl. 3), e482.

Bruno Soares, M., Daly, M., \& Dessai, S. (2018). Assessing the value of seasonal climate forecasts for decision-making. WIRES: Climate Change, 13(3), e523-e519.

Bushell, S., Satre Buisson, G., Workman, M., \& Colley, T. (2017). Strategic narratives in climate change: Towards a unifying narrative to address the action gap on climate change. Energy Research \& Social Science, 28, 39-49.

Daly, M. E., West, J. J., \& Yanda, P. Z. (2016). Establishing a baseline for monitoring and evaluating user satisfaction with climate services in Tanzania. CICERO Report 2016:02. https://drive.google.com/file/d/1pHQ1-ip9fDepjur $5 \mathrm{VbSua-lilJp2d-ok/view.}$

Daron, J. D., Lorenz, S., Wolski, P., Blamey, C., \& Jack, C. (2015). Interpreting climate data visualisations to inform adaptation decisions. Climate Risk Management, 10, 17-26. 
Donkor, F. K., Tantoh, H. \& Ebhuoma, E. (2017). Social learning as a vehicle for catalysing youth involvement in sustainable environmental management. CODESRIA Bulletin 3: Ecologies, economies and societies in Africa. Dakar: CODESRIA.

Ebhuoma, E., \& Simatele, D. (2017). We know our Terrain': Indigenous knowledge preferred to scientific systems of weather forecasting in the Delta state of Nigeria. Climate and Development, 11(2), 112-123. doi:10.1080/17565529. 2017.1374239

Fankhauser, S., \& McDermott, T. (2014). Understanding the adaptation deficit: Why are poor countries more vulnerable to climate events than rich countries? Global Environmental Change, 27, 9-18.

Fløttum, K., \& Gjerstad, O. (2016). Narratives in climate change discourse. Wires Climate Change, doi:10.1002/wcc.429

Gay-Antaki, M., \& Liverman, D. (2018). Climate for women in climate science: Women scientists and the Intergovernmental Panel on Climate Change. PNAS, 115(9), 2060-2065. doi:10.1073/pnas.1710271115

Goldman, M., Turner, M., \& Daly, M. (2018). A critical political ecology of human dimensions of climate change: Epistemology, ontology, and ethics. WIRES: Climate Change, e526.

Hewitt, C., Mason, S., \& Walland, D. (2012). The global Framework for climate services. Nature Climate Change, 2 , 831-832.

Howarth, C. (2017). Telling stories on climate change and low carbon futures: Framing narratives around the UK's fifth Carbon Budget. Journal of Energy Research and Social Science, 31, 295-302.

Howarth, C., \& Black, R. (2015). Local science and media engagement on climate change. Nature Climate Change, 5(6), 506-508.

Howarth, C., Viner, D., Dessai, S., Rapley, C., \& Jones, A. (2017). Enhancing the contribution and role of practitioner knowledge in the Intergovernmental Panel on Climate Change Working Group (WG) II process: Insights from UK workshops. Climate Services, 5, 3-10.

Ivancevic, A. (2017). Surviving academia as an early career researcher: an unreliable guide. Naturejobs blog. http:// blogs.nature.com/naturejobs/2017/10/27/surviving-academia-as-an-ecr-an-unreliable-guide /

Jack, C. (2017). Decision-making for African development and what it means for climate science [Webinar]. Rondebosch: Climate System Analysis Group, UCT.

Jones, M.D., \& Peterson, H. (2017). Narrative persuasion and storytelling as climate communication strategies. Climate Science. Advance online publication. doi:10.1093/acrefore/9780190228620.013.384

McNie, E. C. (2007). Reconciling the supply of scientific information with user demands: An analysis of the problem and review of the literature. Environmental Science and Policy, 10(1), 17-38.

Pereira, T., Shackleton, S. \& Donkor, F. K. (2017). Integrating Climate Change Adaptation (CCA) and Disaster Risk Reduction (DRR) for greater local level resilience: lessons from a multi-stakeholder think-tank. Policy Brief 16. Grahamstown: Department of Environmental Science, Rhodes University.

Petersen, A., Blackstock, J., \& Morisetti, N. (2015). New leadership for a user-friendly IPCC. Nature Climate Change, 5(10), 909-911. doi:10.1038/nclimate2766

Richards, G. W., \& Carruthers Den Hoed, R. (2018). Seven Strategies of climate change science communication for policy change: Combining academic theory with practical evidence from science-policy partnerships in Canada. In L. Filho W., E. Manolas, A. Azul, U. Azeiteiro, \& H. McGhie (Eds.), Handbook of climate change communication: Vol. 2. Climate change management. Cham: Springer.

Street, R. (2016). Towards a leading role on climate services in Europe: A research and innovation roadmap. Climate Services, 1, 2-5.

Suldovsky, B., McGreavy, B., \& Lindenfeld, L. (2018). Evaluating epistemic commitments and science communication Practice in Transdisciplinary research. Science Communication, 40(4), 499-523.

Termonia, P., Schaeybroeck, V., De Cruz, L., De Troch, L., Caluwaerts, S., Giot, O., \& Pottiaux, E. (2018). The CORDEX.be initiative as a foundation for climate services in Belgium. Climate Services, 11, 49-61.

Terrado, M., Christel, I., Bojovic, D., Soret, A., \& Doblas-Reyes, F. J. (2018). Climate change communication and user engagement: A tool to anticipate climate change. In L. Filho W., E. Manolas, A. Azul, U. Azeiteiro, \& H. McGhie (Eds.), Handbook of climate change communication: Vol. 3. Climate change management. Cham: Springer.

Tozier de la Poterie, A., \& Daly, M. (2017). Ethical considerations for just climate services. In B. Hale, \& A. Light (Eds.), The Routledge Companion to Environmental Ethics. London: Routledge.

Vaughan, C., \& Dessai, S. (2014). Climate services for society: Origins, institutional arrangements, and design elements for an evaluation framework. WIRES: Climate Change, 5(5), 587-603.

Vaughan, C., Dessai, S., \& Hewitt, C. (2018). Surveying climate services: What can we learn from a bird's eye view? Weather, Climate and Society, 10(2), 225-239.

Viner, D., \& Howarth, C. (2014). Practitioners' work and evidence in the IPCC reports. Nature Climate Change, 4(10), $848-850$

Whitmarsh, L., \& Corner, A. (2018). Tools for a new climate conversation: A mixed-methods study of language for public engagement across the political spectrum. Global Environmental Change, 42, 122-135. 